Research article

\title{
Traumatic brain injury as a risk factor for Alzheimer disease. Comparison of two retrospective autopsy cohorts with evaluation of ApoE genotype Kurt A Jellinger*1, Werner Paulus ${ }^{2}$, Christian Wrocklage ${ }^{2}$ and Irene Litvan ${ }^{3}$
}

Address: ${ }^{1}$ L.Boltzmann Institute of Clinical Neurobiology, Baumgartner Hoehe 1, B-Bldg., A-1140 Vienna, Austria, ${ }^{2}$ Department of Neuropathology, University of Munster School of Medicine, Munster, Germany and ${ }^{3}$ Cognitive Neuropharmacology Unit, H.M. Jackson Foundation, Bethesda, Md, USA

E-mail: Kurt A Jellinger* - kurt.jellinger@univie.ac.at; Werner Paulus - werner.paulus@uni-muenster.de; Christian Wrocklage - christian.wrocklage@uni-muenster.de; Irene Litvan - ilitvan@dvhip.org

${ }^{*}$ Corresponding author

Published: 30 July 2001

BMC Neurology 200I, 1:3
Received: 29 June 2001

Accepted: 30 July 2001

This article is available from: http://www.biomedcentral.com//47I-2377/I/3

(C) 200I Jellinger et al; licensee BioMed Central Ltd. Verbatim copying and redistribution of this article are permitted in any medium for any non-commercial purpose, provided this notice is preserved along with the article's original URL. For commercial use, contact info@biomedcentral.com

\begin{abstract}
Background and Purpose: The impact of traumatic brain injury (TBI) on the pathogenesis of Alzheimer disease $(A D)$ is still controversial. The aim of our retrospective autopsy study was to assess the impact of TBE and ApoE allele frequency on the development of $A D$.

Material and Methods: We examined I. the incidence of AD pathology (Braak stageing, CERAD, NIA-Reagan Institute criteria) in 58 consecutive patients (mean age \pm SD $77.0 \pm 6.8$ years) with residual closed TBI lesions, and 2. the frequency of TBI residuals in 57 age-matched autopsy proven $A D$ cases. In both series, ApoE was evaluated from archival paraffin-embedded brain material.

Results: I. TBE series: $12.1 \%$ showed definite and 10.3\% probable AD (mean age 77.6 and 75.2 years), only $2 / 13$ with ApoEg3/4. From 45 (77.6\%) non-AD cases (mean age 78.2 years), 3 had ApoEع3/4. The prevalence of $22.4 \% A D$ in this small autopsy cohort was significantly higher than $3.3 \%$ in a recent large clinical series and $14 \%$ in the general population over age 70.2 . In the AD cohort with ApoE\&4 allele frequency of $30 \%$ similar to other AD series, residuals of closed TBI were seen in 4 brains (7\%) (mean age \pm SD $78.2 \pm 6.4$ ), all lacking the ApoEq4 allele. TBI incidence was slightly lower than $8.5 \%$ in the clinical MIRAGE study.

Conclusions: The results of this first retrospective autopsy study of TBI, ApoEE allele frequency, and $A D$ confirm clinical studies suggesting severe $T B I$ to be a risk factor for the development $A D$ higher in subjects lacking ApoE\&4 alleles. Further studies in larger autopsy series are needed to elucidate the relationship between $\mathrm{TBI}$, genetic predisposition, and $\mathrm{AD}$.
\end{abstract}

\section{Introduction}

While some genetic risk factors, e.g. apolipoprotein (ApoE)\&4, predispose the elderly to develop Alzheimer disease (AD), the role of traumatic brain injury (TBI) in the pathogenesis of $\mathrm{AD}$ is still controversial. Accumulating epidemiological evidence implicates TBI as a risk factor for the subsequent development of $\mathrm{AD}$ [for rev. see $[1,2]$, while others reported no such association [see 
[3,4]. In the MIRAGE study, head injury as a risk factor for $\mathrm{AD}$ appeared greater among subjects lacking ApoE\&4 [5]. Among longitudinal studies [6-9], two reported a significantly increased riks of developing $\mathrm{AD}$ in subjects with previous history of TBI [8,9] A recent study of 1776 US World War II navy veterans showed that moderate and severe TBI in early adulthood, rated by the duration of loss of consciousness or posttraumatic amnesia, was associated with increased risk of $\mathrm{AD}$ and dementia in late life (assessed by clinical protocols). The risk increased with the severity of the TBI and showed a nonsignificant trend towards a stronger association between $\mathrm{AD}$ and TBI in men with ApoE\&4 alleles [9]. Although it is well established that deposition of amyloid $\beta$ peptide (A $\beta$ ) known to play an important role in the pathogenesis of $\mathrm{AD}$, in fatal TBI is associated with an ApoEc4 allele $[10,11]$ and that TBI may induce tau pathology with the formation of neurofibrillary tangles, another major histological marker of $\mathrm{AD}[12,13]$, the mechanisms by which TBI may induce the formation of AD pathology are still unknown, and several interpretations have been proposed $[13,14]$. Whereas previous case-control and longitudinal epidemiological studies on the association between TBI and AD were exclusively based on clinical protocols, we present here data of a retrospective autopsy study on the relations between TBI residual lesions, ApoE allele frequency, and $\mathrm{AD}$ pathology.

\section{Material and Methods}

We examined two autopsy series from the research files of the Ludwig Boltzmann Institute of Clinical Neurobiology brain bank, Vienna, Austria, between 1977 and 2000. This material was mainly derived from a large teaching hospital with associated chronic hospital (together around 3000 beds) in Vienna, Austria. In this retrospective study, exact informations about IQ, education, and other major risk factors for $\mathrm{AD}$ were not available. 1. In a consecutive series of 58 patients over age 60 (mean \pm SD $77.0 \pm 6.8$ ) years with residual closed TBI pathology we looked for the incidence of AD pathology. 2. In a consecutive series of 57 age-matched autopsy proven $\mathrm{AD}$ cases (mean \pm SD age 77.6 \pm 7.3 years) we looked for the presence of morphological TBI residuals. All patients were Caucasians and immunocompetent. All brains were examined histologically using routine stains including modified Bielschowsky silver stain and immunohistochemistry with a battery of antibodies against $\mathrm{ABl}-42$, PHF tau (antibody AT-8), ubiquitin, and $\alpha$-synuclein for the demonstration of Lewy bodies. The classification of $\mathrm{AD}$ was performed according to the Khachaturian criteria [15], the Consortium to Establish a Registry for Alzheimer Disease (CERAD) criteria [16], the Braak stageing of neuritic Alzheimer lesions [17], and the National Institute on Aging (NIA)-Reagan Institute classification for the postmortem diagnosis of $\mathrm{AD}$ [18]. Evaluation of
ApoE alleles was performed in all cases of both cohorts from archival paraffin-embedded brain material using a semi-nested PCR method [19]. Since ApoE genotyping was performed retrospectively in cohort 1 , no controls for older, non-TBI subjects were available. Statistical evaluation was performed using Chi-square test and the Mann-Whitney U-test.

\section{Results \\ I. TBE series}

Among the 58 autopsy cases over age 60 with residuals of closed TBI of various degrees and distribution, 7 brains or $12.1 \%$ ( 4 males and 3 females aged 69 to 83 , mean \pm SD $77.6 \pm 6.4$ years, revealed the pathological features of definite $\mathrm{AD}$, i.e. Khachaturian positive, $\mathrm{CERAD}$ $B$ or $C$, Braak stages 5 or 6 , with a great likelihood of $A D$ as cause of dementia according to the NIA-Reagan criteria. Only one of them exhibited ApoE\&4, all the others were $\varepsilon 3 / 3$ and $\varepsilon 2 / 3$ ( 3 each). All these brains, in addition to severe neuritic $\mathrm{AD}$ pathology showed posttraumatic lesions of limited extent and various distribution, mainly old contusions in bilateral frontobasal areas $(n=1)$, frontotemporal $(\mathrm{n}=1)$, right frontobasal and temporal $(\mathrm{n}=2)$ with additional old cerebellar contusion $(n=2)$, and right frontal pole $(n=1)$. TBI history dated back 10 to 30 years prior to the death, but was unknown in 2 of these patients. The duration of $\mathrm{AD}$ ranged from 4 to 7 years. Two additional $\mathrm{AD}$ cases -2 males aged 69 and 82 years, respectively - were excluded since the TBI due to falls had occurred 2 to 4 months prior to death after the development of severe dementia. Both brains showed definite AD (CERAD C, Braak stage 5); both were ApoE ع2/3. Further 6 cases or 10.3\% (3 men and women each, aged $65-85$, mean \pm SD $75.2 \pm 6.4$ years) were pathologically classified "probable" $\mathrm{AD}$, meeting positive Khachaturian criteria, CERAD B, Braak 3 or 4; with intermediate likelihood of $\mathrm{AD}$ as cause of dementia according to the NIAReagan criteria; only one of them had ApoE\&3/4 allele, the others $\varepsilon 3 / 3$ or $\varepsilon 2 / 3$. In these patients, closed TBI had occurred between 8 and 39 years prior to death and many years before development of cognitive impairment, the duration of which ranged from 3 to 7 years. Neuropathology, in addition to AD lesions, revealed bilateral old traumatic contusional deficits or scars in frontobasal and temporopolar areas $(n=2)$, in the right frontopolar and temporal, and in the left frontobasal and temporal or in the left parietal region (2 cases each). None of these subjects had a history of chronic alcoholism, Korsakoff syndrome or any morphological signs of Wernicke encephalopathy or essential concomitant cerebrovascular lesions except for occasional mild lacunar state in the basal ganglia. None of them meet the morphological criteria for mixed type dementia (combination of $\mathrm{AD}$ and vascular encephalopathy), of Parkinson disease (PD) or of dementia with Lewy bodies (DLB) [20]. 
In the remaining 45 non- $\mathrm{AD}$ cases $(77.6 \%$; 36 men and 9 women aged 61 to 85 , mean \pm SD $78.2 \pm 7.8$ years), the ApoE allele frequency was $\varepsilon 3 / 3(n=39), \varepsilon 3 / 4$ and $\varepsilon 2 / 3$ $(\mathrm{n}=3$ each) comparable to that in the general aged population [21-23]. Old traumatic brain lesions in this cohort were seen mainly in the frontobasal, frontopolar and temporopolar areas, less frequently frontobasal and frontopolar or temporal/ temporopolar unilaterally or bilaterally. In two of these cases (aged 85 and 86 years), neuropathology revealed additional PD of the Lewy body type with no only very few cortical Lewy bodies, thus excluding DLB [20].

\section{2. $A D$ cohort}

Among 57 consecutive autopsy cases of definite $\mathrm{AD}$ aged 71 to 91 years with a mean \pm SD of $77.6 \pm 7.3$ years the ApoeEc4 allele frequency was $30 \%(\varepsilon 4 / 4 n=6 ; \varepsilon 3 / 4 n=$ 11) which was comparable to that in other $\mathrm{AD}$ series ranging from 24 to $38 \%$ [21-25]; all the others were $\varepsilon 3 /$ 3 or $2 / 3$. Residuals of closed TBI were seen in 4 brains or 7.0 \%, 2 men and women each aged 71-91 (mean \pm SD $78.2 \pm 5.6)$ years, all lacking ApoeEc4 alleles. They had suffered closed head injuries 7 to 54 years prior to death and, like in cohort 1 , many years before onset of cognitive deterioration. A male dying at age 71 years has suffered a blow to the right parietal region with several hours unconsciousness 54 years prior to death; two women aged 76 and 91 years had suffered TBI with unknown duration of unconsciousness in car accidents 7 and 30 years before death, and a male aged 75 years had TBI with short unconsciousness due to a fall on the occiput 8 years prior to death, and a duration of $\mathrm{AD}$ of about 2 years. None of them had experienced repeated TBI as boxers or other sportsmen. Neuropathology, in addition to definite $\mathrm{AD}$ changes (Khachaturian positive, CERAD stage B or C, Braak stages 4 or 5 , i.e. intermediate or high likelihood of $\mathrm{AD}$ as the cause of dementia according to the NIA-Reagan criteria), revealed old contusional scars in the frontobasal and temporal areas $(n=3)$ and in the parietal region $(n=1)$.

\section{Discussion}

To the best of our knowledge, this is the first study to detect $\mathrm{AD}$ pathology in a consecutive autopsy series of posttraumatic brain lesions and to look for the presence of residual brain lesions of closed TBI in a cohort of autopsy proven $\mathrm{AD}$ cases. The prevalence of $22.3 \%$ of probable and definite $\mathrm{AD}$ in a rather small cohort of subjects with a mean age of 75 to 77.6 years and residuals of closed TBI is considerably higher $(\mathrm{p}<0.001)$ than $3.3 \%$ in the recent clinical US series of VA subjects who sustained moderate to severe TBI during World War II [9]. It was also higher than the prevalence of AD in the general Caucasian population showing a wide range between 3 and $11 \%$ for those older than 65 years $(p<0.001)$, about $14 \%$ for those older than 70 , and between 7 and $50 \%$ for subjects older than 85 years [26-31]. In comparison to $\mathrm{AD}$ patients showing an ApoE\&4 prevalence of 24 to $38 \%$ [2125 ], it was only $15.4 \%$ in the present cohort of AD cases with residual TBI lesions. The extent and distribution did not seem to influence later developrent of AD. Since in the majority of the patients later developing $\mathrm{AD}$, TBI history 10 to 30 years prior to death and the mean age of these patients was comparable to the non-AD cases, one might exclude the possibility that a greater injury may have a bigger effect on $\mathrm{AD}$ development, especially when interacting with older age which is the most significant factor in $\mathrm{AD}$ [see [1]]. Since in this retrospective study no exact information on pre-morbid intellectual levels and education were available, no suggestions about brain reserve capacity (BRC) as a potential moderating factor on risk variables related to $\mathrm{AD}$ expression can be made.

The prevalence of residuals of previous closed TBI in $7 \%$ of a consecutive series of autopsy-proven $\mathrm{AD}$ aged 71 to 91 (mean $77.6 \pm 7.3$ ) years, all lacking an ApoEع4 allele, was slightly lower than in the large clinical MIRAGE study, where TBI with loss of consciousness in $\mathrm{AD}$ probands was reported in 8.5\% [5]. This study like ours indicates that closed head injury is a higher risk factor for the development of $\mathrm{AD}$ among subjects lacking ApoEe4 alleles compared to those having them. This is in accordance with recent experimental data showing that transgenic mice expressing human ApoE\&4 are more susceptible than those expressing ApoEع3 to closed head injury, probably related to a protective effect of ApoEs3 and an ApoE\&4-related pathological function [32].

In conclusion, the results of this first retrospective study on the association of TBI and ApoE allele frequency on the development of $\mathrm{AD}$ confirm clinical studies suggesting some influence of severe TBI on the development of $\mathrm{AD}$, being a higher risk factor for $\mathrm{AD}$ among subjects lacking ApoEe4 alleles compared to those having them. However, further studies in larger autopsy series of TBI and $\mathrm{AD}$ are needed to further elucidate the relationshipt between closed TBI, ApoE allele, and the development of $\mathrm{AD}$.

\section{Competing interests}

None Declared

\section{Acknowledgements}

The authors are grateful to Mrs V. Rappelsberger for skilled laboratory work and to Mr E. Mitter-Ferstl, PhD, for secretarial assistance. The study was funded in part by the Austrian Federal Ministery of Education and Science and by the Austrian Parkinson Society.

\section{References}

I. Lye TC, Shores EA: Traumatic brain injury as a risk factor for Alzheimer's disease: a review. Neuropsychol Rev 2000, I 0: I I5-129 2. Gottlieb S: Head injury doubles the risk of Alzheimer's disease. Brit Med J 2000, 321 : 1 100 
3. Launer LI, Andersen K, Dewey ME, Letenneur L, Ott A, Amaducci LA, Brayne C, Copeland JR, Dartigues JF, Kragh-Sorensen P, et al: Rates and risk factors for dementia and Alzheimer's disease: results from EURODEM pooled analyses. EURODEM Incidence Research Group and Work Groups. European Studies of Dementia. Neurology 1999, 52:78-84

4. Mehta KM, Ott A, Kalmijn S, Slooter AJ, van Duijn CM, Hofinan A, Breteler MM: Head trauma and risk of dementia and Alzheimer's disease: The Rotterdam Study. Neurology 1999, 53:19591962

5. Guo Z, Cupples LA, Kurz A, Auerbach SH, Volicer L, Chui H, Green RC, Sadovnick AD, Duara R, DeCarli $C$, et al: Head injury and the risk of AD in the MIRAGE study. Neurology 2000, 54:I316-I323

6. Katzman R, Aronson M, Fuld P, Kawas C, Brown T, Morgenstem H, Frishman W, Gidez L, Eder H, Ooi WL: Development of dementing illnesses in an 80-year-old volunteer cohort. Ann Neurol 1989, 25:317-324

7. Williams DB, Annegers JF, Kokmen PC, O'Brien PC, Kurland LT: Brain injury and neurologic sequelae: a cohort study of dementia, parkinsonism, and amyotrophic lateral sclerosis. Neurology 1991, 41:1554-1557

8. Schofield PW, Tang M, Marder K, Bell K, Dooneief G, Chun M, Sano $M$, Stem Y, Mayeux R: Alzheimer's disease after remote head injury: an incidence study. J Neurol Neurosurg Psychiatry 1997, 62:119-124

9. Plassman BA, Havlik BA, Steffens BA, Helms BA, Newman BA, Drosdick BA, Phillips BA, Gau BA, Welsh-Bohmer KA, Burke JR, et al: Documented head injury in early adulthood and risk of Alzheimer's disease and other dementias. Neurology 2000, 55:1158-1166

10. Nicoll JAR, Roberts GW, Graham DI: Apolipoprotein E\&4 allele is associated with deposition of amyloid $\beta$-protein following head injury. Nature Med 1995, I:135-137

II. Horsburgh K, Cole GM, Yang F, Savage BD, Greenberg BD, Gentleman SM, Graham DI, Nicoll JAR: $\beta$-Amyloid (A $\beta$ ) 42(43), A $\beta$ 42, $A \beta 40$ and apo $E$ immunostaining of plaques in fatal head injury. Neuropathol Appl Neurobiol 2000, 26:124-132

12. Smith C, Graham DI, Nicoll JAR: Tau immunohistochemistry in acute head injury. Neuropathol Appl Neurobiol 200I, 27:15I

13. Geddes JF, Vowles GH, Nicoll JA, Revesz T: Neuronal cytoskeletal changes are an early consequence of repetitive head injury. Acta Neuropathol 1999, 98:17I-178

14. Graham DI, McIntosh WL, Maxwell WL, Nicoll JAR: Recent advances in neurotrauma. J Neuropathol Exp Neurol 2000, 59:64I651

15. Khachaturian ZS: Diagnosis of Alzheimer's disease. Arch Neurol 1985, 42:1097-II05

16. Mirra SS, Heyman A, McKeel D, Sumi SM, Crain B], Brownlee LM, Vogel FS, Hughes JP, Van Belle G, Berg L: The Consortium to establish a registry for Alzheimer's disease (CERAD) II. Standardization of the neuropathologic assessment of Alzheimer's disease. Neurology 1991, 41:479-486

17. Braak H, Braak E: Neuropathological stageing of Alzheimerrelated changes. Acta Neuropathol 1991, 82:239-259

18. Hyman BT, Trojanowski JQ: Editorial on Consensus recommendations for the postmortem diagnosis of Alzheimer disease from the National Institute on Aging and the Reagan Institute Working group on diagnostic criteria for the neuropathological assessment of Alzheimer disease. J Neuropathol Exp Neurol 1997, 56:1095-1097

19. Wrocklage C, Bernatik J, Stefan H, Jellinger KA, Paulus W: Apolipoprotein $E$ genotype in epilepsy and schizophrenia patients with cognitive deficits. Acta Neuropathol 1999, 99:557

20. McKeith IG, Galasko D, Kosaka K, Perry EK, Dickson DW, Hansen LA, Salmon DP, Lowe J, Mirra SS, Byrne EJ, et al: Clinical and pathological diagnosis of dementia with Lewy bodies (DLB): report of the CDLB International Workshop. Neurology 1996, 47:1 II3-III24

21. Harrington CR, Louwagie J, Rossau R, Vanmechelen E, Perry RH, Perry EK, Xuereb JH, Roth M, Wischik CM: Influence of apolipoprotein $E$ genotype on senile dementia of the Alzheimer and Lewy body types. Significance for etiological theories of Alzheimer's disease. Am J Pathol 1994, 45: | 472-I 484

22. Egensperger R, Bancher C, Kösel S, Jellinger K, Mehraein P, Graeber MB: The apolipoprotein E\&4 allele in Parkinson's disease with
Alzheimer lesions. Biochem Biophys Res Commun 1996, 224:484486

23. Bancher C, Egensperger R, Kösel S, Jellinger K, Graeber MB: Low prevalence of apolipoprotein $\mathrm{E} \varepsilon 4$ allele in the neurofibrillary tangle predominant form of senile dementia. Acta Neuropathol 1997, 94:403-409

24. Corder EH, Lannfelt L, Bogdanovic N, Fratiglioni L, Mori H: The role of apoe polymorphisms in late-onset dementias. Cell Molec Life Sci 1998, 54:928-934

25. Rebeck GW, Peris TT, West HL, Sodhi P, Lipsitz LA, Hyman BT: Reduced apolipoprotein epsilon 4 allele frequency in the oldest old Alzheimer's patients and cognitively normal individuals. Neurology 1994, 44:1513-1516

26. Geldmacher DS, Whitehouse PJ: Evaluation of dementia. N Eng I Med 1996, 335:330-336

27. Reischies FM, Geiselmann B, Gessner R, Kanowski S, Wagner M, Wemicke F, Helmchen H: Demenz bei Hochbetagten. Ergebnisse der Berliner Altersstudie. Nervenarzt 1997, 68:719-729

28. Thomassen R, van Schaick HW, Blansjaar BA: Prevalence of dementia over age 100. Neurology 1998, 50:283-286

29. Bachman DL, Wolf PA, Linn R, Knoefel JE, Cobb J, Belanger A, RB D'Agostino, White LR: Prevalence of dementia and probable senile dementia of the Alzheimer type in the Framingham Study. Neurology 1992, 42:115-119

30. Pfeffer RI, Afifi AA, Chance JM: Prevalence of Alzheimer's disease in a retirement community. Am J Epidemiol I 987, I 25:420436

31. Hy LX, Keller DM: Prevalence of AD among whites. A summary by levels of severity. Neurology 2000, 55:198-204

32. Sabo T, Lomnitski L, Nyska A, Beni S, Maronpot RR, Shohami E, Roses $A D, D M$ : Michaelson: Susceptibility of transgenic mice expressing human apolipoprotein $E$ to closed head injury: the allele E3 is neuroprotective whereas E4 increases fatalities. Neuroscience 2000, 10 I:879-884

\section{Pre-publication history}

The pre-publication history for this paper can be accessed here:

http://www.biomedcentral.com/content/backmatter/ 1471-2377-1-3-b1.pdf

Publish with BioMed Central and every scientist can read your work free of charge

"BioMedcentral will be the most significant development for disseminating the results of biomedical research in our lifetime." Paul Nurse, Director-General, Imperial Cancer Research Fund

Publish with BMC and your research papers will be:

- available free of charge to the entire biomedical community

- peer reviewed and published immediately upon acceptance

- cited in PubMed and archived on PubMed Central

- yours - you keep the copyright

Submit your manuscript here:

http://www.biomedcentral.com/manuscript/ 